\title{
Evaluation of Three Different Enamel Roughening Method: an SEM and Photographic Study IE Gelgor ${ }^{1}$, B Catalbas ${ }^{2}$, F Bilgic $^{3}$
}

\begin{abstract}
Objective: To evaluate the effect of three different enamel roughening method on the bond strength of metal brackets bonded to enamel surfaces with light-cured composite resin, and also to determine less harmful the roughening method on the enamel by SEM and photographic methods.

Methods: Forty two metal brackets and newly extracted premolar teeth were divided into three groups ( $\mathrm{n}=14$ for each group). The specimens were randomly assigned to one of the following rough conditions of the teeth surfaces: Roughening with (Group 1) conventional 37\% orthophosphoric acid, (Group 2) 18\% HCL and pumice (microabrasion) and (Group 3) sandblasting with $50 \mu$ alumina particles. The all surfaces were photographically examined and additional two teeth surfaces in each group were examined for SEM. Brackets were bonded to the enamel surface on the premolars with a light-polymerized resin composite. All specimens were stored in water for 1 week at $37^{\circ} \mathrm{C}$ and then thermocycled. The shear bond strength values were measured on a universal testing machine. $\mathrm{P}$ values less than or equal to .05 were considered statistically significant.

Results: The specimens in Group 1 and 2 had significantly greater bond strength values. There were no statistically differences between the groups. However Group 3 showed relatively low values $(7.79 \pm 5.94 \mathrm{MPa})$ than the control group $(\mathrm{P}<.001)$. Enamel roughening method by $18 \%$ HCL and pumice gave clinically the finest enamel surface.
\end{abstract}

Conclusions: Microabrasion of the teeth with $18 \%$ HCL and pumice can be alternative tooth roughening method for bonding of brackets to enamel. After microabasion, occurred fine polished surfaces on the enamel give an easiness dental plaque control during orthodontic treatment.

Keywords: Bond strength, enamel roughening, microabrasion, stainless steel brackets

From: Professor Kirikkale, The University, School of Dentistry, Department of Orthodontics, Kirikkale, Turkey, School of Dentistry, Faculty of Dentistry, Department of Orthodontics, Kirikkale, Turkey, Mustafa Kemal University, School of Dentistry, Department of Orthodontics, Hatay, Turkey.

Correspondence: Dr IE Gelgor, The University of Kirkkale, Faculty of Dentistry, Department of Orthodontics 71100, Kirkkale, Turkey. Fax: +903-182-250685, e-mail: egelgor@aol.com

DOI: 10.7727.wimj.2015.096 


\section{INTRODUCTION}

Bond strength of brackets has a direct impact on the success of orthodontic treatment. This strength is produced with a mechanical bond between microporosity of bracket base and tooth surface. A number of techniques have been reported about surface roughness method. But literature survey identified very few studies that examine surface roughness method protocols whether have maximum bond strength which is enough to prevent failure, and the damage to the enamel or minimum damage to the tooth surface.

A number of techniques have been reported to increase bond strength of brackets $(1,2)$. The etching technique that uses $37 \%$ phosphoric acid is the most common among these applications. The enamel must be etched for 15-30 seconds with 37\% phosphoric acid. But acid etching time could be reduced to 15 seconds for younger permanent teeth is recommended (3, 4). Acid etching that uses phosphoric acid results in good bond strength but an enamel loss ranging from 3 to $10 \mu \mathrm{m}(5,6)$. Maleic and polyacrylic acids may be used instead of phosphoric acid in order to decline the enamel loss (7).

Another suggested approach for surface roughening is macroetching with aluminum oxide particles using an intraoral sandblaster (8). It has been indicated that a better bond system with less enamel loss is obtained by the air-abrasive technique which uses of a high-speed stream of aluminum oxide particles (9). Satisfactory bond strength is obtained with sandblasting, but in case of prolonged application time, material loss from the enamel surface and surface roughness might be increased with no increase in bond strength (10-13).

Hydrochloric acid (HCL) especially used for the treatment of the white spot lesions that occur after orthodontic treatment and microabrasion technique with pumice can be used for enamel preparation before orthodontic bonding. In our previous study (14), a mixture of $\% 18 \mathrm{HCL}$ and 
Table 2: ANOVA results of differences between groups for bond strenght pumice (an abrasive) which were used to remove of the white spot lesions. Macroscopic evaluation has been shown that superfine polished, smooth and luster enamel surfaces were achieved after this procedure. Croll and Cavanaugh $(9,15)$ and Bishara $(16)$ applied the mixture of $\% 18 \mathrm{HCL}$ and pumice to enamel surfaces by a wooden spatula. They remarked that this procedure didn't damage the enamel surface. At the microscopic level the procedure generate surface roughness on the enamel (14).

The purpose of this investigation is to compare using three methods of enamel preparation before orthodontic bonding that are currently in use and to determine that which method produces higher bond strength and minimal risk of iatrogenic damage to the enamel surface.

\section{MATERIALS AND METHODS}

Forty two extracted human premolars without caries were collected and stored in $0.9 \%$ saline solution (Biofarma, Turkey). Three groups were constituted and each group contained 14 (plus 2 for SEM examination) specimens which selected at random. In group 1 that served as control group, the enamel surfaces were etched with $37 \%$ orthophosphoric acid gel (Prime Dent, USA) for 40 seconds, then rinsed with waterspray for 30 seconds, and air-dried 15 seconds.

The teeth in group II were cleaned with 18\% HCL (Altan Chemistry, Kirikkale, Turkey) and pumice mixture (microabrasion) by micromotor for 15 seconds (14), then rinsed for 30 seconds, and air-dried for 15 seconds. In this way, it was seen chalky image on the enamel that is surface roughness was observed to allow bracket bonding. 
The teeth in group III are abraded with $50 \mu$ aluminum oxide $\left(\mathrm{Al}_{2} \mathrm{O}_{3}\right)$ for $2-3$ seconds by a microetcher in a macro cab (Danville Engineering Inc, USA), then compressed air was applied for 15 seconds to the teeth for remove sandblasting powder.

\section{Photographic Investigation of Surface Appearance}

To evaluate the teeth surface after sandblasting, all specimens were pressed into a mold to be fitted the standard distance from the camera, in order to examine the appearance of the surface. Using a standard digital camera (Nikon D 200 Nikon corp, Japan) with macrolens (105 mm, Nikon corp, Japan ), the standard vestibular surface images with standard distance and 300 pixels/cm resolution images of samples from all groups were obtained (Figure 1). All images of the tooth surface by giving points from 1 to 5 were scored in accordance with the untreated surface appearance of a tooth surface for tooth surface flatness and smoothness $(9,14)$, (Table 1). Scoring was made by only one investigator by FB. Wilcoxon Signed Ranks test was used for the evaluation of differences between the groups.

\section{Investigation of the View Surface with SEM}

Two teeth from all groups were investigated with Scanning Electron Microscope (SEM, JSM5600, JEOL Ltd., Tokyo, Japan) for comparing with each other.

Silverstone et al. (17) and Galil and Wright (18) remarked that 5 different roughness models were occurred after roughening of teeth surfaces.

Type 1: The occurrence of a honeycomb appearance with the disintegration of the enamel prisms from the center.

Type 2: Cobblestone appearance of the enamel prisms formed by dissolving the periphery. 
Table 2: ANOVA results of differences between groups for bond strenght Type 3: A mixture of type 1 and 2.

Type 4: Appearance of the enamel with the pit surfaces that resemble to the incomplete puzzle Type 5: Smooth surface.

In our study, investigation of tooth surfaces by SEM study was based on these five criteria (Figure 2).

Investigation Bond Strength of Roughness Methods

42 premolar brackets (Generous-Roth, stainless steel, GAC International, Bohemia, NY) were bonded to sample teeth with light-curing bonding agent (Light Bond, Reliance Orthodontic Products, Ithaca, III) as prescribed in the literature. All specimens were thermocycled for 5000 cycles between 5 and $55^{\circ} \mathrm{C}$ using a dwell time of 30 seconds after stored in distilled water at $37^{\circ} \mathrm{C}$ for 1 week. Shear bond strength of each specimen was measured with an universal testing machine (Lloyd-LRX; Lloyd Instruments, Fareham, UK). Descriptive statistics were made for each group. In addition, ANOVA was used to determine differences between groups and intergroups. P value less than .05 was considered statistically significant ones.

\section{RESULTS}

Investigation of Tooth Surfaces

The scores in each group after the photographic examination are shown in Table 2. In all groups "Microabrasion" has given the best views in terms of tooth surface flatness and smoothness (Figure 1, Table 2).

In the SEM examination with X500 (a) and X2000 (b) magnification, it is observed that the nearest appearance to the original enamel surface is seen on the group II which are applied "microabrasion" roughening method (Figures $2 \mathrm{a}, \mathrm{b}$ ). 
Type 4 roughening model characterized by recesses is observed on the tooth surfaces which applied traditional roughening method with using orthophosphoric acid (Figures 3 a,b). The more uniform tooth surface is obtained with microabrasion roughening method and Type 5 roughening model have occurred (Figures $4 \mathrm{a}, \mathrm{b}$ ). After sandblasting with using microetcher, tooth surfaces show irregular structures which are not match in the all roughening models (Figures 5 a,b).

\section{Investigation of Bond Strength}

Bond strengths along the standard deviation of each group are shown in Table 3. Roughening with phosphoric acid and microabrasion groups showed largest bond strength values (Group 1:

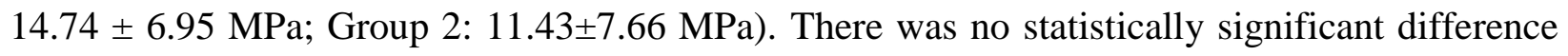
between the two groups. However, the sandblasting group (Group 3) had lower value than the values of the control group $(7.79 \pm 5.94 \mathrm{MPa}),(\mathrm{P}<.001)$, (Table 3).

\section{DISCUSSION}

Roughening with $37 \%$ phosphoric acid of enamel is a traditional method and is called "microetching". Also cleaning of the enamel surface with $18 \% \mathrm{HCL}$ and pumice is called "microabrasion". In a similar manner, roughening by sandblasting is known as the "macroetching" (10). Macroscopically sufficient roughening in the enamel surface can be achieved in all three methods. Gelgor and Buyukyilmaz (14) reported that a polished surface which reduces microbial dental plaque retention was obtained at the end of the process of cleaning the enamel surface with $18 \% \mathrm{HCL}$ and pumice. In our study has been found that the best view of the tooth surfaces can be achieved with microabrasion technique in the macroscopic evaluation (Figure 1). Researchers $(10,19)$ reported that the tooth surfaces which were 
Table 2: ANOVA results of differences between groups for bond strenght roughened with sandblasting were created smooth surfaces look like natural tooth surfaces after when were cleaned with tire rubber and pumice. Gerbo et al. (11) found that when the enamel was cleansed using rubber cup and pumice or the air powder polisher for enemal preparation, there was no prominent difference in placement of orthodontic brackets. In our research, macroscopic appearance of the tooth surfaces which occurred after roughening by sandblasting are better than orthophosphoric acid group, however worse than microabrasion group (Table 1). These findings are supported by SEM images (Figures 2-5). Especially highly irregular tooth surfaces were seen in group 3 (Figure 5).

To achieve the clinically adequate bonding, bond strength between enamel and metal brackets should be 6-8 MPa (20-22). In our study, the mean bond strength of all our groups were found to be clinically adequate $(>7 \mathrm{MPa})$. These findings also suggest that the three methods may be used for bonding of the metal brackets to enamel. However van Waveren Hogervorst et al. (7) reported that could be obtained the adequate surface roughness, but not enough bond force with the sandblaster with aluminum oxide $(50 \mu \mathrm{m})$. Buyukyilmaz and Zachrisson (12) indicated that surface preparation should be done with sandblasting to increase the bond strength especially to amalgam, gold and porcelain. Canay et al. (13) reported that when enemal was sandblasted with $50 \mu$ aluminumoxide by a microetcher followed by acid etched with $37 \%$ phosphoric acid, the highest tensile strength was obtained. But bond strengths obtained with sandblasting with a microetcher alone are not sufficient.

Similarly, this study showed the bond strength values in Groups 1 and 2 were significantly higher than those of sandblasting group. The reason may be that the surface formed by sandblasting for bonding could be narrower than the enamel surface prepared by etching (13). The biggest drawback of the roughening by sandblasting is the lack of enough practice of the 
clinical applicability. If the roughening will be applied in the oral environment, the strong aspirator and rubber dam is needed to prevent of the sandblasting material spreading. Otherwise, the scattered sandblasting materials can irritate the cheek mucosa and cause pollution in the practice environment.

Prior to roughening with traditionally $37 \%$ phosphoric acid, teeth cleaning with pumice is recommended especially when the tooth surface is discolored with external factors and is covered with debris. In this way, the tooth surface contact area will be increased and more roughening surface will be emerged by acid etching. In this study, the tooth cleaning with $18 \%$ HCL and pumice and acid etching of the tooth surface has applied in the same visit by means of micro abrasion. The chair time for patients in group 2 has been noticeably decreased before orthodontic bonding. A polished and plaque free enamel surface has come forward (Fig 6).

\section{CONCLUSION}

In this study, it is determined through both of the photographic and SEM images that microabrasion method gave the closest results with the appearance of the original tooth surface. Because of the bond strength values that were obtained with the microabrasion method by $18 \%$ HCL and pumice, were close by conventional $37 \%$ phosphoric acid method, can be an alternative roughening method before orthodontic bonding. Fine polished enamel surface that was occurred after the microabrasion, can provide the convenience of dental plaque control during the orthodontic treatment. 
Table 2: ANOVA results of differences between groups for bond strenght

\section{REFERENCES}

1. Bradburn G, Pender N. An in vitro study of the bond strength of two light-cured composites used in the direct bonding of orthodontic brackets to molars. Am J Orthod Dentofacial Orthop 1992;102:418-426.

2. Atsu S, Catalbas B, Gelgor IE. Effects of silica coating and silane surface conditioning on the bond strength of rebonded metal and ceramic brackets. J Appl Oral Sci 2011;19:233239.

3. Livaditis GJ. A chemical etching system for creating micromechanical retention in resinbonded retainers. J Prosthet Dent 1986;56:181-188.

4. van der Veen JH, Jongebloed WL, Dijk F, Purdell-Lewis DJ, van de Poel AC. SEM study of six retention systems for resin-to-metal bonding. Dent Mater 1988;4:266-271.

5. Wang WN, Yeh CL, Fang BD, Sun KT, Arvystas MG. Effect of H3PO4 concentration on bond strength. Angle Orthod 1994;64:377-382.

6. Barkmeier WW, Gwinnett AJ, Shaffer SE. Effects of enamel etching time on bond strength and morphology. J Clin Orthod 1985;19:36-38.

7. van Waveren Hogervorst WL, Feilzer AJ, Prahl-Andersen B. The air-abrasion technique versus the conventional acid-etching technique: A quantification of surface enamel loss and a comparison of shear bond strength. Am J Orthod Dentofacial Orthop 2000;117:2026.

8. Newman GV, Newman RA, Sun BI, Ha JL, Ozsoylu SA. Adhesion promoters, their on the bond strength of metal brackets. Am J Orthod Dentofacial Orthop 1995;108:237-241.

9. Croll TP, Cavanaugh RR. Enamel color modification by controlled hydrochloric acidpumice abrasion. II. Further examples. Quintessence Int 1986;17:157-164. 
10. Reisner KR, Levitt HL, Mante F. Enamel preparation for orthodontic bonding: a comparison between the use of a sandblaster and current techniques. Am J Orthod Dentofacial Orthop 1997;111:366-373.

11. Gerbo LR, Lacefield WR, Wells BR, Russell CM. The effect of enamel preparation on the tensile bond strength of orthodontic composite resin. Angle Orthod 1992;62:275-281.

12. Buyukyilmaz T, Zachrisson BU. Improved orthodontic bonding to silver amalgam. Part 2. Lathe-cut, admixed, and spherical amalgams with different intermediate resins. Angle Orthod 1998;68:337-344.

13. Canay S, Kocadereli I, Ak"ca E. The effect of enamel air abrasion on the retention of bonded metallic orthodontic brackets. Am J Orthod Dentofacial Orthop 2000;117:15-19.

14. Gelgör IE, Büyükyilmaz T. A practical approach to white spot lesion removal. World J Orthod 2003;4:152-156.

15. Croll TP, Cavanaugh RR. Enamel color modification by controlled hydrochloric acidabrasion. I. technique and examples. Quintessence Int 1986;17:81-87.

16. Bishara SE, Denehy GE, Goepferd SJ. A conservative postorthodontic treatment of enamel stains. Am J Orthod Dentofacial Orthop 1987;92:2-7.

17. Silverstone LM, Saxton CA, Dogon IL, Fejerskov O. Variation in the pattern of acid etching of human dental enamel examined by scanning electron microscopy. Caries Res $1975 ; 9: 373-387$.

18. Galil KA, Wright GZ. Acid etching patterns on buccal surfaces of permanent teeth. Pediatr Dent 1979;1:230-234.

19. Peutzfeldt A, Asmussen E. Silicoating: evaluation of a new method of bonding composite to metal. Scand J Dent Res 1988;96:171-176. 
Table 2: ANOVA results of differences between groups for bond strenght

20. Gillis I, Redlich M. The effect of different porcelain conditioning techniques on shear of stainless steel brackets. Am J Orthod Dentofacial Orthop 1998;114:387-392.

21. Bourke BM, Rock WP. Factors affecting the shear bond strength of orthodontic brackets to porcelain. Br J Orthod 1999;26:285-290.

22. Cochran D, O'Keefe KL, Turner DT, Powers JM. Bond strength of orthodontic composite cement to treated porcelain. Am J Orthod Dentofacial Orthop 1997;111:297-300. 


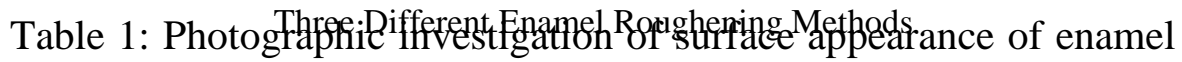
after the preparation.

\begin{tabular}{llll}
\hline & Group I & Group II & Group III \\
\hline Specimens & $\begin{array}{l}37 \% \\
\text { Orthophosphoric } \\
\text { acid gel }\end{array}$ & $\begin{array}{l}18 \% \text { HCL and } \\
\text { pumice mixture }\end{array}$ & $\begin{array}{l}50 \\
\text { aluminum } \\
\text { oxide }\end{array}$ \\
1 & 3 & 1 & 3 \\
2 & 4 & 2 & 2 \\
3 & 3 & 1 & 3 \\
4 & 2 & 1 & 2 \\
5 & 4 & 2 & 2 \\
6 & 4 & 1 & 3 \\
7 & 3 & 1 & 3 \\
8 & 3 & 2 & 3 \\
9 & 4 & 1 & 2 \\
10 & 2 & 1 & 3 \\
11 & 3 & 2 & 2 \\
12 & 3 & 1 & 2 \\
13 & 4 & 1 & 3 \\
14 & 3 & 1 & 3 \\
Mean & 3,2 & 1,3 & 2,6 \\
\hline
\end{tabular}

Roughening models of teeth surfaces

\begin{tabular}{lllll}
\hline 1 & 2 & 3 & 4 & 5 \\
very good & good & moderate & bad & very bad
\end{tabular}


Table 2: ANOVA results of differences between groups for bond strenght

\begin{tabular}{lllll} 
Groups & $\mathrm{N}$ & Mean & Standard Deviation & $\mathrm{P}$ \\
\hline Group I (37\% Orthophosphoric acid gel ) & 14 & 3,20 & 0,79 & NS \\
Group II (18\% HCL and pumice mixture ) & 14 & 1,30 & 0,48 & NS \\
Group III (50 $\mu$ aluminum oxide) & 14 & 2,60 & 0,52 & NS \\
Total & 42 & 2,37 & 0,60 & \\
\hline
\end{tabular}

NS: No significant

Table 3: ANOVA results of differences between groups for bond strength.

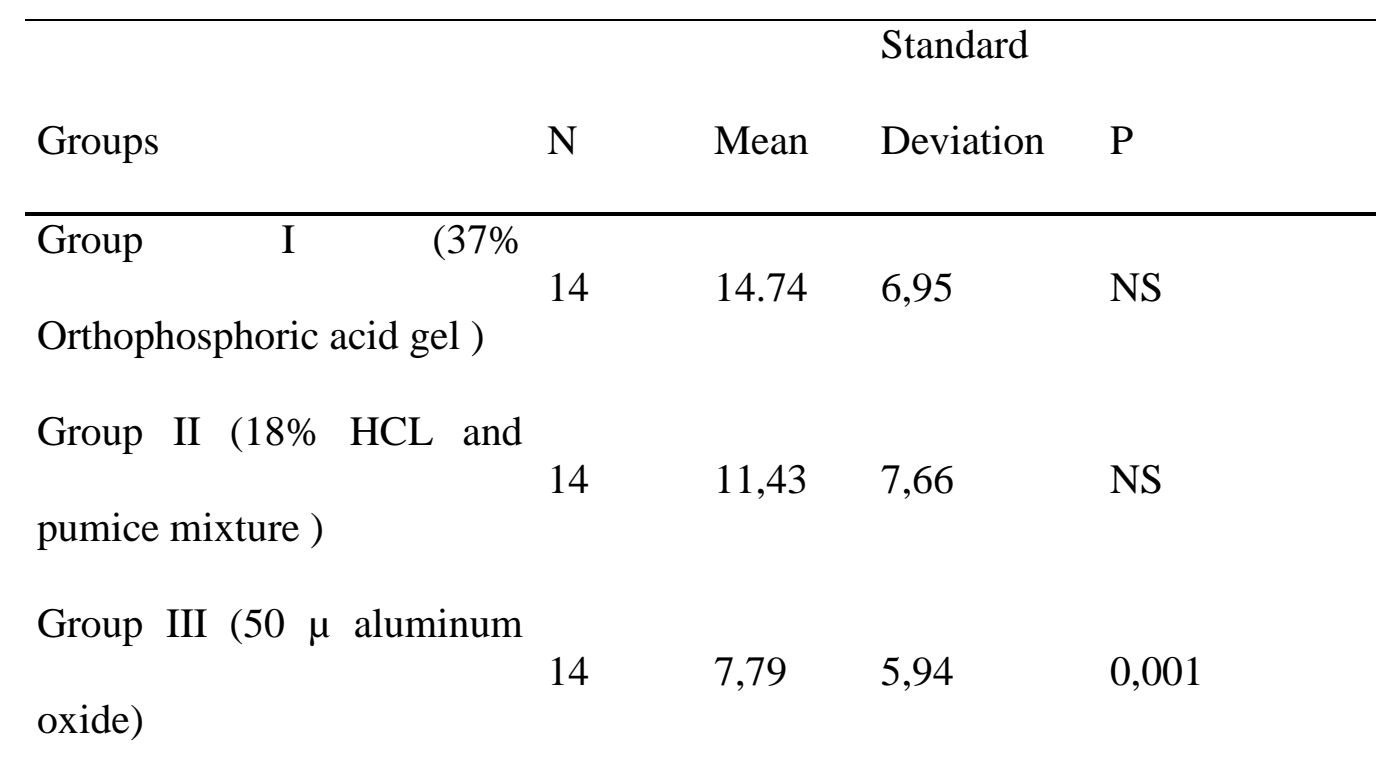



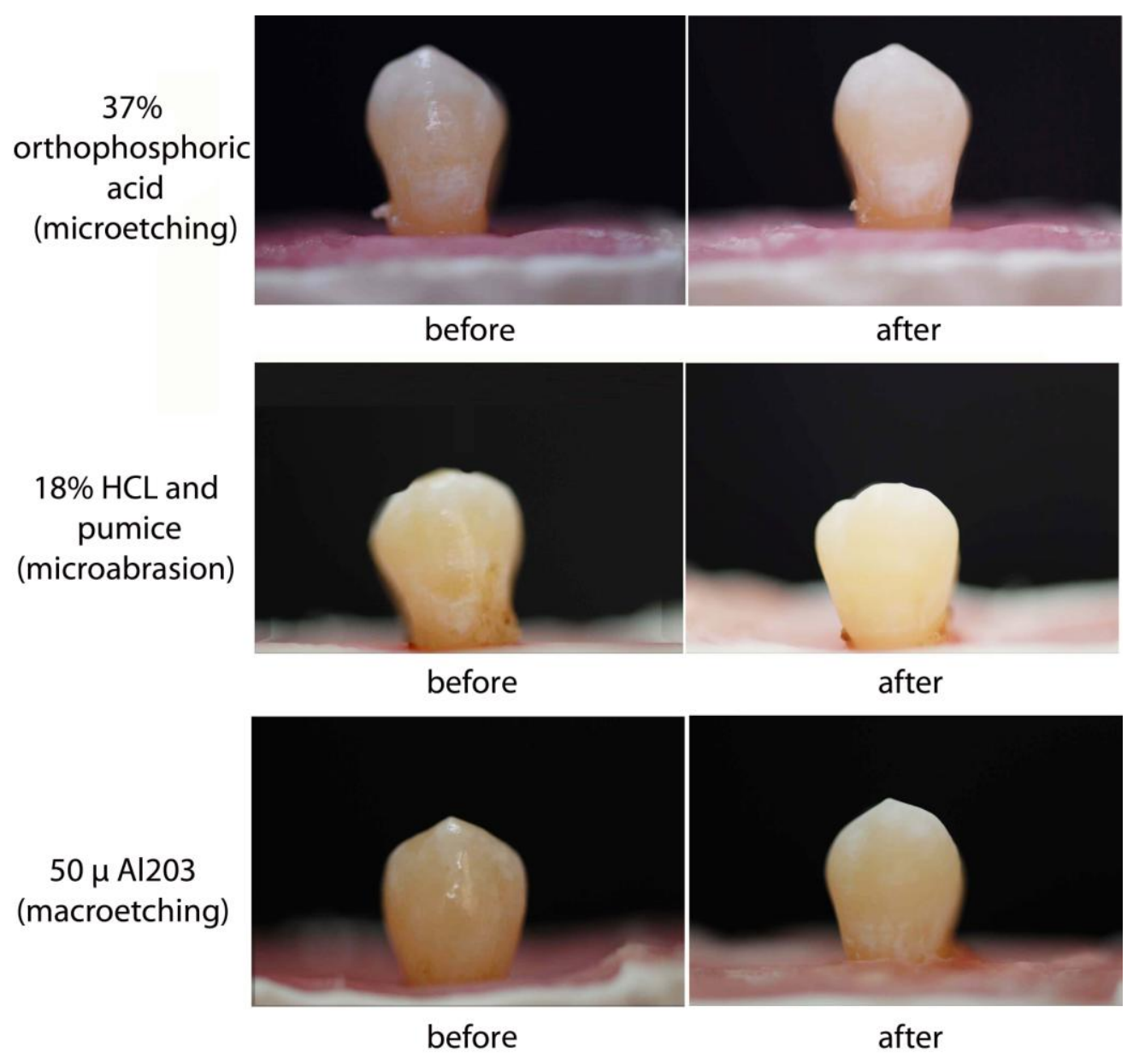

Figure 1: The photographic examination of the teeth before and after three different enamel preparation methods. 
Table 2: ANOVA results of differences between groups for bond strenght

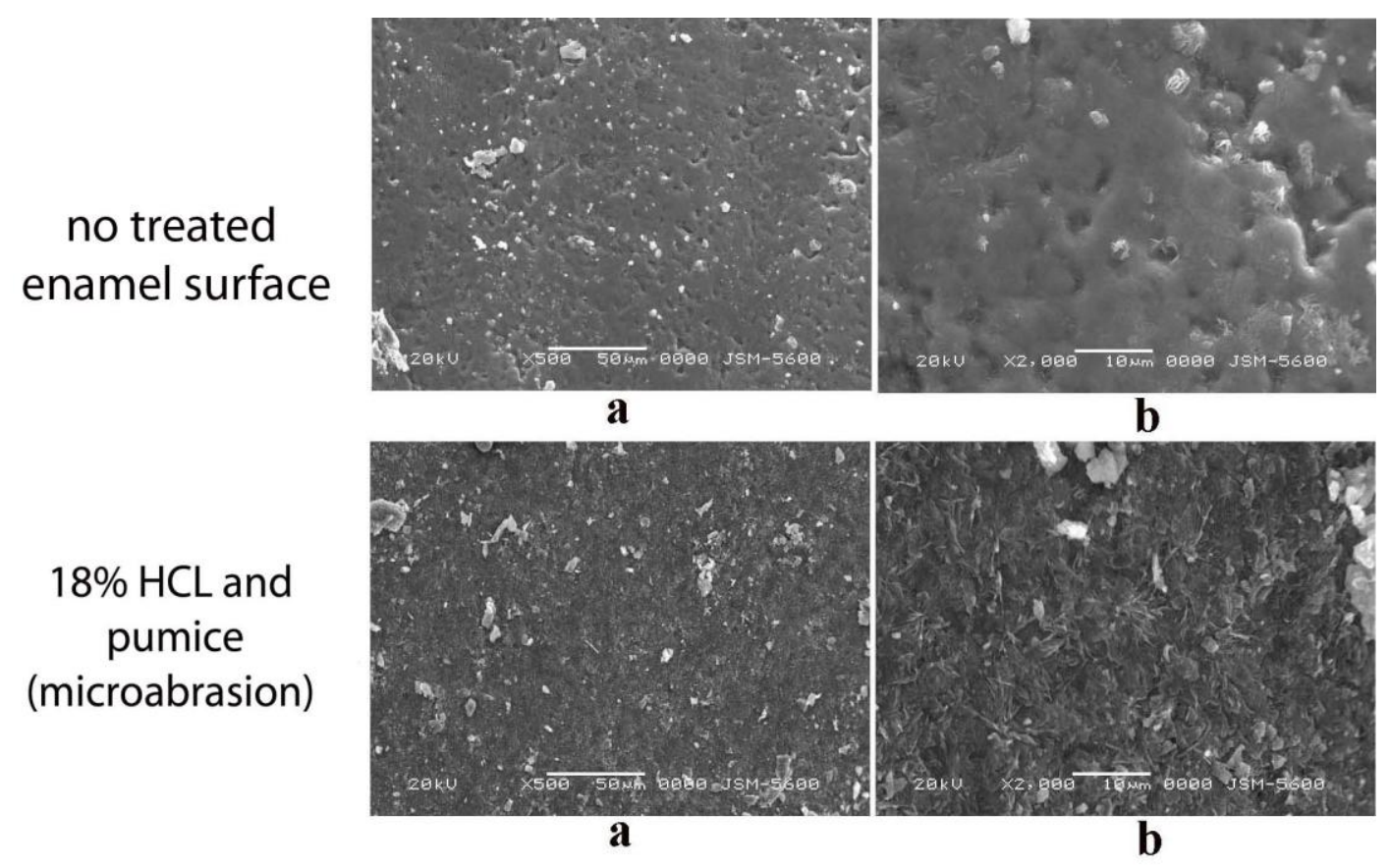

Fig.2: Comparison enamel surfaces with no treated and the microabrasion at SEM (a:X500 and b:X2000 magnifications).

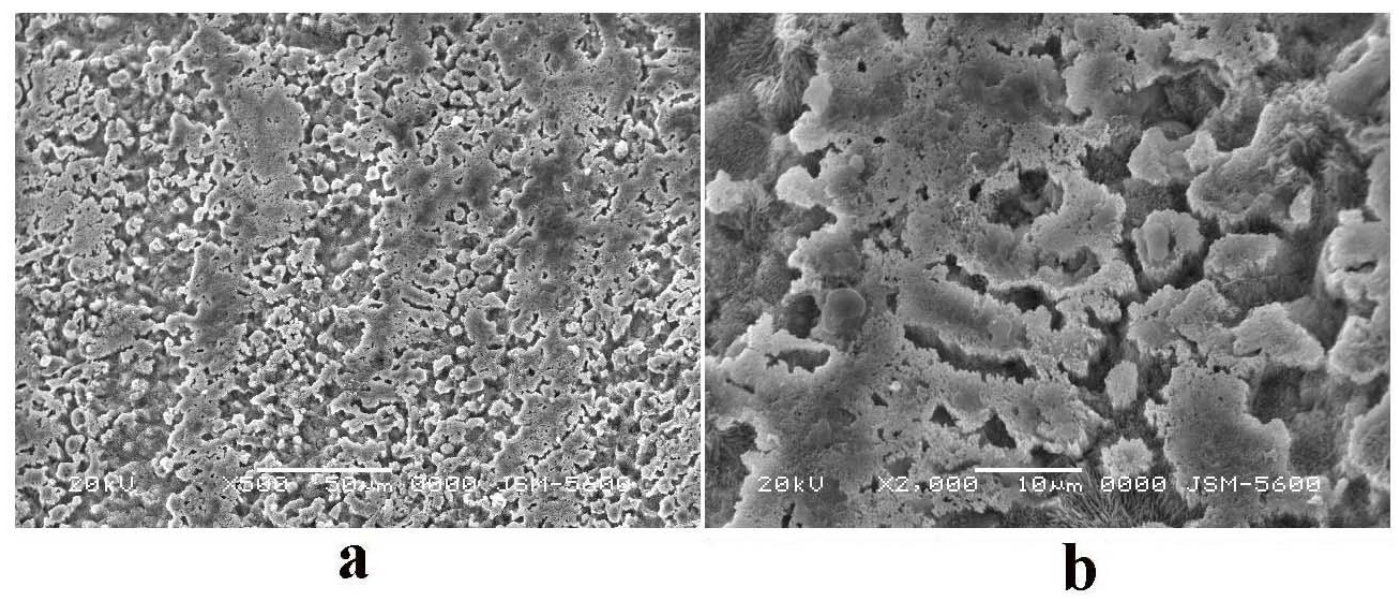

Fig.3: SEM examination at X500 (a) and X2000 (b) magnification of enamel surface the orthophosphoric acid applied. 


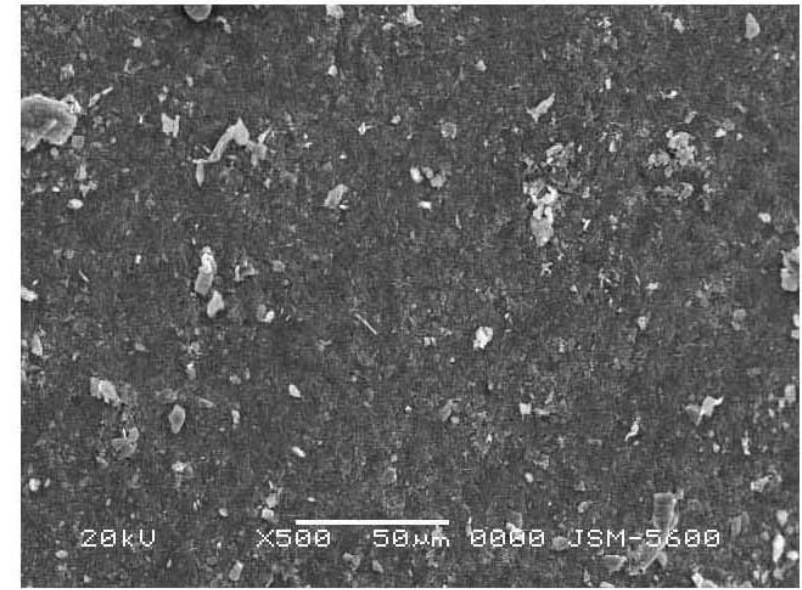

a

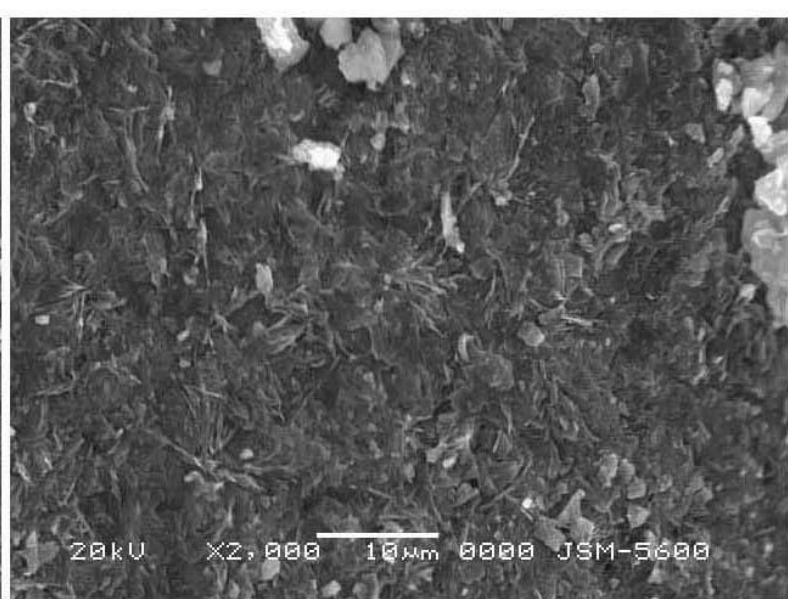

b

Fig.4: SEM examination at X500 (a) and X2000 (b) magnification of enamel surface the microabrasion applied.

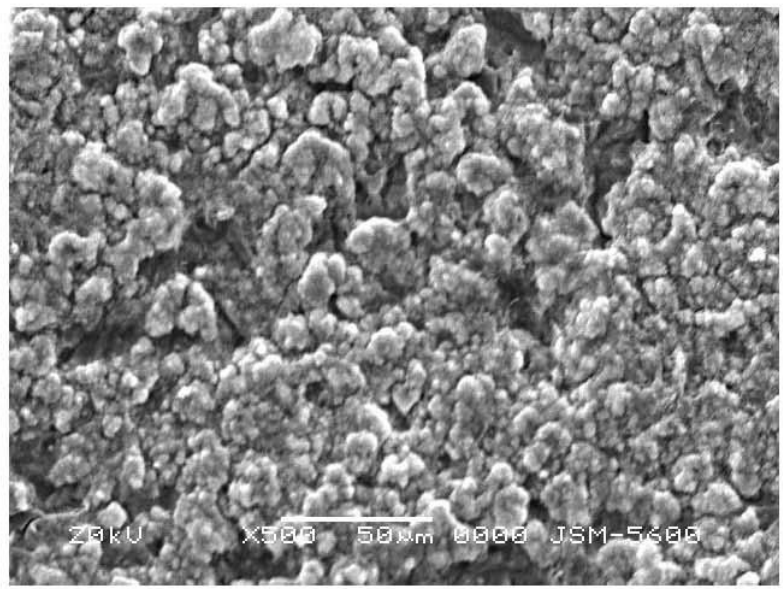

a

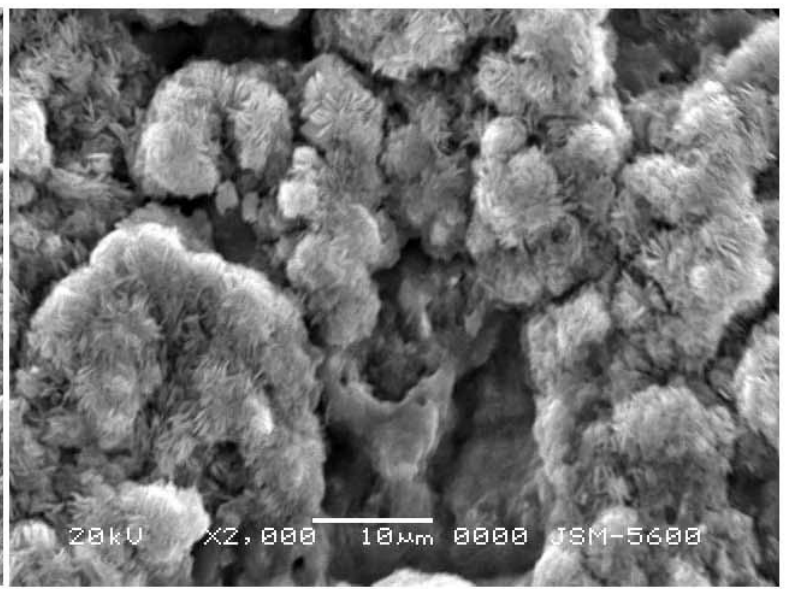

b

Fig.5: SEM examination at X500 (a) and X2000 (b) magnification of enamel surface the macroetching applied. 
Table 2: ANOVA results of differences between groups for bond strenght

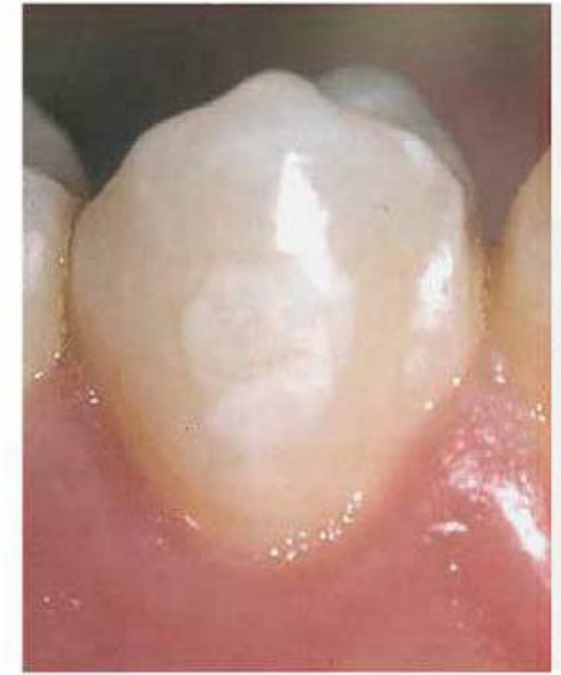

before

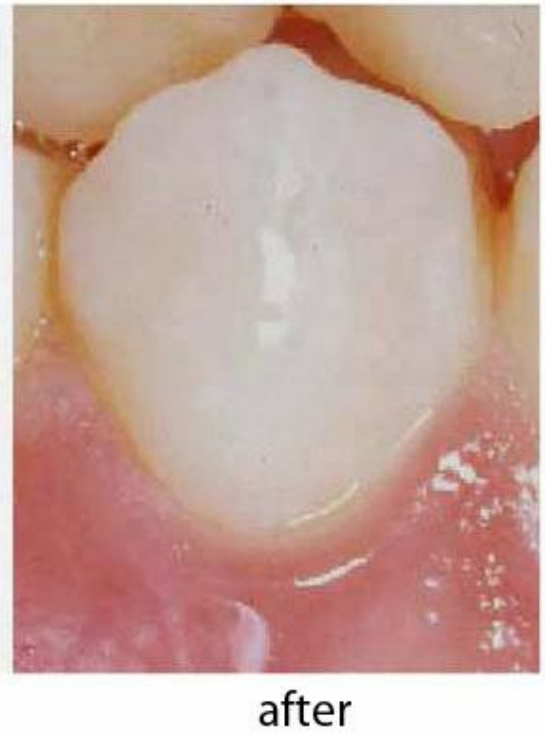

Fig.6: A polished and without retention surface appearance of the enamel to be cleaned with $18 \%$ HCL and pumice mixture. 
Three Different Enamel Roughening Methods 